\title{
图书馆知识管理对图书馆管理的创新
}

\author{
王新皎 \\ 山东省泰山学院图书馆 \\ DOI:10.12238/ej.v3i4.513
}

\begin{abstract}
[摘要] 随着社会的发展和人民生活水平的不断提高, 我国的图书馆行业也迎来了一个较快的发展时 期。为进一步提高图书馆的管理水平, 完善图书馆的管理职能, 将图书馆的功能得以最大化的呈现, 那么 就要把知识管理应用其中。知识管理是图书馆的主要工作内容之一, 良好的知识管理质量是提高图书馆 服务水平的有效方式。在图书馆的管理中,对知识管理进行创新, 能够确保对图书馆稳定的可持续性发展 进行实现。文章通过分析图书馆管理创新的意义及现状,进而提出创新策略。
\end{abstract}

[关键词] 图书馆; 知识管理; 创新

中图分类号：G251 文献标识码：A

\section{1 图书馆知识管理的内容}

图书馆是一个知识管理的专门的机 构, 承担着保存人类文化遗产, 开展社会 教育、传递科学情报和开发智能力资源 的社会职能, 同时这些也是图书馆知识 管理的内容。

对知识的概念有不同的理解, 对以 知识为对象的知识管理也会有各种看法 和观念。很多人会用藏书册数来判断和 评价一个图书馆的水平。由于知识对物 质载体具有强烈的依赖性, 所以有的人 将物质载体的数量与知识量对等起来, 简单地把知识管理与知识载体的管理混 为一谈。这不是我们所说的知识管理, 这是一种见物不见人的管理, 这种只是 对图书文献的管理, 是对物的管理, 没有 将人与信息联结, 与工厂仓库对机器部 件的管理无甚区别。图书馆的知识管理, 不是机械地对图书文献的管理, 而是要 通过对物的管理来实现对知识的管理, 体现以人为本, 为知识的传播和利用作 服务, 推动知识的创新, 促进城市精神文 明的发展。

\section{2 图书馆进行知识管理的意义 分析}

图书馆是人们学习的主要场所, 在 当前的时代发展形势下, 与之前相比, 人 们对于学习的需要发生了根本性的转变, 因此对于图书馆来说, 应该积极转变传
统的管理和服务观念, 积极进行管理模 式的变革和升级, 这样才能更好地满足 当代人们的学习需要, 这也是图书馆长 远发展的必经之路。在管理实践中, 读者 的实际需求是图书馆管理的主要参考指 标, 不管采取怎样的管理方式, 其最为根 本的目的都是为了提高读者的学习体验, 进而更好地服务于读者, 提高图书馆的 发展水平。一直以来, 信息管理都是图书 馆管理的主要形式, 但是随着当前读者 需求的变化和发展, 传统的信息管理模 式已经不能适应读者的实际需要, 更加 优化的知识管理模式才是提高图书馆管 理水平的有效途径。因此对于图书馆来 说, 应该及时摒弃传统的管理模式和管 理理念, 充分发挥知识管理的优势, 促进 图书馆服务创新发展。

\section{3 图书馆创新管理的现状}

国内许多图书馆在管理水平方面都 较低, 管理方式主要体现为由上级向下 级直接传达命令或工作要求, 下级就按 部就班地进行图书馆的管理。一般上级 在指定图书馆管理方案时往往是依据相 关经验并没有去专门的了解相关的管理 知识。盲目的制定管理方案就容易造成 与现实生活脱节的情况, 让下级难以完 成工作。上下级缺乏沟通也是其中的一 个重要的问题, 许多领导下达完指令后 只看结果, 没有重视下级具体的工作情
况、工作过程, 忽视了下级的感受。在薪 资方面也没有建立切实有效的激励机制, 导致了下级在工作时缺乏激情, 工作效 率低下, 与上级领导关系恶化。信息化水 平较低, 大多数图书馆在统计方面依旧 采用的是手工统计, 导致图书馆内许多 信息的归类出现问题, 读者在查询相关 信息书籍时费劲。这些问题日积月累就 会很大程度上的影响图书馆的管理, 更 影响图书馆今后的发展。

\section{4 现阶段图书馆管理的影响} 因素

4. 1管理人员缺乏知识管理理念

现在许多图书馆都已经开始着手于 图书馆知识管理方面的建设, 但是仍然 有许多工作人员缺乏这方面的管理理念, 相应的管理层也没有对此表示出足够的 重视, 这对图书馆日后的建设和发展是 不利的。

4. 2 图书馆的管理体制

在我国, 现阶段图书馆的管理体制 和管理方法与世界其他发达国家相比较 为落后, 信息化管理体系的建设还不到 位, 尤其是图书馆知识管理体系的建设 依然有待加强。

\section{3管理的方式与方法 \\ 传统的图书馆管理体系以人工监管} 为主。这种落后的监督和管理模式需要 动用大量的人力和物力资源, 而且效率 
不高。因此, 在图书馆的管理上引入现代 化的管理体系就显得十分重要。

\section{5 基于知识管理的图书馆管理} 创新

5. 1 加大对管理理念的创新

图书馆知识管理遵循人本思想, 将 人本资本管理作为主要核心, 将知识创 新与服务作为主要的管理目标。基于信 息化背景下, 图书馆建设为了更好地适 应当前的时代发展, 一定从思想观念开 始进行创新, 受到图书馆管理目标的影 响, 图书馆在知识管理期间, 一定要对原 有的观念与方法进行不断调整, 将资源 共享作为图书馆管理的主要理念, 实现 在思想上的有效转变。一是将图书馆建 设由一般性转为特色性, 在做好图书馆 分工的基础上, 开展网络化资源建设。二 是图书馆在进行特色化建设期间, 突出 自身的存取功能。当前, 有必要将图书馆 资料按照需求印刷成电子版, 从而不断 提升图书馆的存取能力。

5.2运用图书知识管理对图书馆管 理系统模式的创新

图书馆管理十分复杂, 包含图书馆 内容、人力资源分配等方方面面, 在图朽 馆知识管理系统中可以更加细化, 分为 事务模式、专家模式、集成模式、协作 模式等。图书馆知识管理事务模式以知 识的规范为核心, 促使知识的标准化形 成, 促进知识系统化、规范化、自动化运 用。图书知识管理专家模式以专家为中 心开展工作, 发挥专家的价值吸引更多 的人投入到图书馆知识的海洋中。图书 馆知识管理集成模式关注整体的发展, 图书馆管理是一个整体, 需要各方面相 互协调、相互促进发展, 促使各部门互帮 互助团结友爱发展。图书馆管理协作模
式纵观全局, 使各方面协调、互帮互助解 决问题, 各部门相互激励、共同促进、共 同发展、资源共享。

5.3 管理内容方面的创新

对人事管理、行政管理以及业务管 理等进行全方位的创新。第一传播管理, 将信息及时地传递到读者, 实现二者的 有效配置; 第二满足读者不同层次的需 要, 对单位以及企业的需求进行全面了 解, 为其提供更加全面的服务; 第三更好 的进行人力资源管理, 设置专门的学习、 培训机构, 培养出更多的优秀人才; 第四 改变研究对象, 将知识作为研究的主要 对象, 以知识作为管理的主线, 探索新的 知识管理途径, 对现有的管理理念进行 创新, 不断地进行完善; 第五进行知识服 务以及管理, 为知识管理提供更加有力 的发展条件, 从而促进自身更好的发展。

5. 4对图书馆的信息服务水平进行 大幅度的提高

在图书馆传统的管理过程中, 只重 视自身的发展, 完全对服务进行忽视, 但 是图书馆的核心就是服务, 所以图书馆 对知识管理进行应用, 能够确保对图书 馆的管理进行准确的定位, 促使图书馆 能够回归服务的本质, 不断对服务理念 进行深化, 从而确保图书馆能够为读者 提供更加周到、全面的服务。而且随着 我国社会不断进入多媒体时代, 促使图 书馆传统的信息受到极其严重的威胁, 因此图书馆需要对知识管理进行改革, 才能够确保对读者的需求进行充分的满 足, 从而促使图书馆的发展与社会的发 展相适应。

5.5 从知识应用的角度对知识管理 进行创新

当前, 在图书馆的整个知识管理体
系当中, 特别要注意加强数字化和虚拟 图书馆的资源建设。从对人们日常信息 查询和浏览的情况来进行分析, 充分的 满足广大服务群体在信息方面的基本需 求, 所以数字化和虚拟图书馆的资源建 设, 既可以通过搜索的功能, 收集广大读 者的需求, 也能够通过对需求的满足不 断的丰富资源, 从而提高服务的能力。所 以, 知识管理进行的创新, 可以更多的考 虑, 人们日常在知识获取信息检索方面 的一般习惯, 特别是在当前信息技术发 展的大背景之下, 数字化图书馆已经成 了人们知识获取的重要的途径。所以, 图书馆要提高自身的服务意识, 重点加 强数字化和虚拟图书馆的建设, 能够不 断地满足人们的需求。

\section{6 结语}

在新时代, 图书馆管理应该不断地 创新, 提高知识的传播及对社会发展的 作用, 更好地满足读者的需求。在这个 过程中图书馆应该不断地加强学习及 培训, 提高自身的能力, 不断地引进科 技信息化技术, 并应用到阅读的体验及 图书馆的创新管理中。加强图书馆的人 性化管理让图书馆更好地为读者服务, 并把知识管理的理念更好地应用到图 书馆管理中。

\section{[参考文献]}

[1]孟维炜.分析知识管理在党 校图书馆管理中的应用 [J]. 教 师,2019,(23): 121-122.

[2]李小格. 图书馆馆员隐性知识外 部化存在的问题分析 [J]. 区域治 理,2019,(32):151-153.

[3]王静.关于新时代下加强中职学 校图书馆创新管理的思考 [J]. 国际教育 论坛,2020,2(3):51-52. 